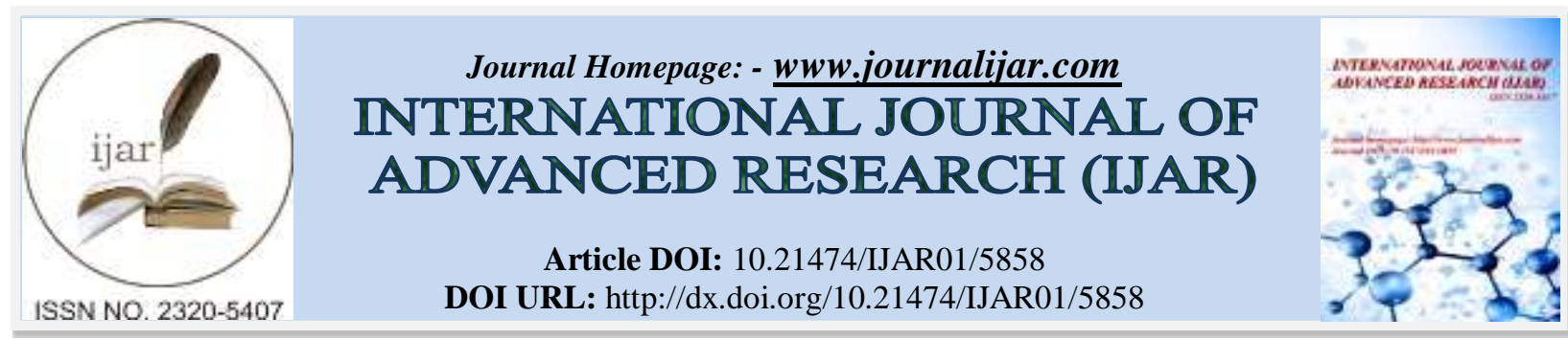

RESEARCH ARTICLE

\title{
MINI-IMPLANT- VERSUS CONVENTIONAL IMPLANT-RETAINED MANDIBULAR OVERDENTURE IN COMPLETELY EDENTULOUS PATIENTS: A SYSTEMATIC REVIEW AND META-ANALYSIS.
}

\author{
Marwa Hassan Mostafa ${ }^{1,2}$, Ali Abdulghani AlSourori ${ }^{2,3}$, Amal Fathy Kaddah ${ }^{4}$ and Ahmed Emad Fayyed ${ }^{5}$ \\ 1. Assistant Researcher, Department Of Fixed And Removable Prosthodontics, National Research Center, Egypt \\ 2. PhD Candidate Prosthodontics, Faculty of Oral and Dental Medicine Cairo University, Egypt. \\ 3. Lecturer of Prosthodontics, Faculty of Dentistry, Ibb University, Yemen. \\ 4. Head of Department Of Prosthodontics, Faculty of Oral and Dental Medicine Cairo University, Egypt. \\ 5. Assistant Professor at Faculty of Oral and Dental Medicine Cairo University, Egypt.
}

\section{Manuscript Info}

\section{Manuscript History}

Received: 14 September 2017

Final Accepted: 16 October 2017

Published: November 2017

Key words:-

Mini Implant, Conventional Implant,

Implant Mandibular Overdenture,

Patient Satisfaction, Survival Rate,

Marginal Bone Loss.

\begin{abstract}
Purpose: The aim of this study was to evaluate the impact of mini implant versus conventional implant mandibular overdenture on patients' satisfaction and survival and success rates.

Material and methods: A comprehensive electronic searching in PubMed and Cochrane databases up to March 2017 with language restriction to English only. We include randomized controlled trials compare between mini implant versus conventional implant regarding patient's satisfaction, survival rate, marginal bone loss and complications. In addition, a manual searching was performed for related journals from January 2013 to March 2017. A meta-analysis was performed on all included studies by using a random effect model [mean, 95\% confidence intervals $(\mathrm{CI})$ ] to pool the effect size as a heterogeneity between studies was high $\left(\mathrm{P}<0.0001\right.$ and $\left.\mathrm{I}^{2}=88 \%\right)$.

Result: Primary screening and manual searching result in 124 articles from which only 5 articles compatible with our inclusion criteria. No statistically significance was found between mini implant versus conventional implant mandibular overdenture regarding patient satisfaction, survival rate, marginal bone loss and fracture incidence (confidence interval $\mathrm{CI}=95$ and $p=0.39$ ).

Conclusion: There is no strong evidence to reveal that mini implant could be used in the same degree as conventional dental implant however mini dental implant could be used as an alternating choice to conventional dental implant.
\end{abstract}

Copy Right, IJAR, 2017,. All rights reserved.

\section{Introduction:-}

Compromised retention, stability and support of conventional complete denture especially lower denture directly affect the patient confidence, function, comfort and bring a major challenge for prosthodontics. (Fitzpatrick BT 2006, Burns 2000)

(Burns 2000) concluded that bone reduction that occur in the alveolar ride will result in diminished tissue mucosal support which adversely affecting functional properties of the denture ending in poorly fitted denture. 
(Burns 2000) stated that utilizing dental implants to retain over-denture will provide excellent benefits than conventional denture essentially due to bone preservation around implant and inhibition of further bone loss.

(Doundoulakis et al 2003) Stated that implant supported over denture have a higher success rate furthermore it promote patient satisfaction, denture retention and stability and they concluded that implant supported over-denture should be the first choice when treating completely edentulous patients.

(The McGill consensus) instituted that mandibular over dentures retained by two implants in the inter foramina area should be the first choice standard of care for the edentulous patient.(Feine et al 2002)

Overdentures supported by conventional implants display good long-term results however; some limitations are present such as: cost (Ribeiro et al 2015) difficultly with the implant insertion in reduced buccolingual dimensions of bone without the need for bone-grafting procedures (Aparecido et al 2016) and the occurrence of chronic systemic diseases that can preclude most progressive surgeries as bone grafts and lateralization of the inferior alveolar nerve (Aparecido et al 2016),(Preoteasa et al 2010).

Mini implants may be reflected as a treatment option for the rehabilitation of patients who have revealed dissatisfaction with conventional dentures and have limitations in the placement of standard implants (Aparecido et al 2016),(Bidra \& Almas 2013),(de Souza et al 2015). Mini implants enable the use of less-complex surgical techniques since the reduced diameter of the implant permits its placement in areas with low bone thickness

On the other hand, there is no consensus supporting the use of mini implants to retain overdentures in the literature; some studies on this subject have verified great survival rates for overdentures retained by mini implants (Aparecido et al 2016),(Preoteasa et al 2014), and other studies have testified low survival rates compared with conventional implants (de Souza et al 2015).

Therefore, the goal of this systematic review was to verify the feasibility of using mini implants to retain overdentures. The assumptions of this study were: (1) There is no difference regarding the survival rates between mini implants retaining overdenture prosthesis compared with standard implants; (2) Mini implants do not affect marginal bone loss, satisfaction, or quality of life.

\section{Materials and Methods:-}

This systematic review accomplished according to the Preferred Reporting Items for Systematic Reviews and MetaAnalyses (PRISMA).(Moher et al 2009)

\section{Research Question:-}

For mandibular implant retained over denture patients will the use of mini implants retained over denture result in different satisfaction, quality of life, implant loss and prosthetic maintenance when compared with standard implant retained over denture?

\section{PICO Format:-}

P - Mandibular retained over dentures

I - mini implants

C- Standard implants

O- Patient satisfaction, quality of life, Implant survival rate, and prosthetic maintenance.

A prior protocol for This systematic review was created and registered in at PROSPERO International prospective register of systematic reviews (PROSPERO: CRD42017068623).

\section{Search Strategy:-}

The Pub Med and Cochrane databases will be searched for published articles until March 15-2017. Regarding language we plan to restrict research to English language only. In addition, a manual search was performed from references and from the journals: Clinical implant dentistry and related research, Clinical Oral Implants Research, Journal of prosthodontics and Journal of prosthetic dentistry 


\section{The following search terms were performed:-}

mandibular overdentures OR mandibular overdenture OR mandibular over-dentures OR mandibular over-denture OR mandibular overlay dentures OR mandibular overlay denture OR mandibular overlay prosthesis OR mandibular overlay prostheses OR lower overdentures OR lower overdenture OR lower overdentures OR lower overlay dentures OR lower overlay prosthesis OR lower over-denture OR lower over_denture OR lower over_dentures OR lower over-dentures OR mandibular stabilized overdenture OR mandibular anchored overdenture OR mandibular assisted overdenture OR mandibular retained overdentures AND $((()((()(($ mini dental implant) OR mini dental implants) OR mini implants) OR mini implant) OR single piece dental implant) OR single piece dental implants) OR one piece dental implant) OR narrow dental implants) OR little dental implants) OR small dental implant) OR minute dental implant) OR tiny dental implant AND $((()(()((($ conventional dental implant) OR conventional dental implants) OR standard dental implant) OR standard dental implants) OR regular dental implant) OR normal dental implant) OR normal dental implants) OR typical dental implant) OR average dental implant) OR usual dental implants) OR conventional implant) OR standard implant

\section{Eligibility criteria:-} Inclusion criteria:-

1. Studies of management of completely edentulous patients with conventional implant or mini implant

2. Articles published in English

3. Randomized control trial

4. Humans trial

\section{Exclusion criteria:-}

1. Animal study

2. Vitro study

3. Articles published other than English

4. Studies other than RCT

5. Systematic review study

\section{Outcome Measures:-}

The survival rates of implant supported mandibular overdenture were determined by percentage. While the prosthetics maintenances and complications were considered as dichotomous outcomes (no of events in each attachment designs).

Disagreement between reviewers (MH, AA,) was resolved by the observer (AK). The kappa agreement was calculated.

\section{Quality and Risk of Bias Assessment:-}

The Quality assessment of included studies was performed using the Cochrane Collaboration tool for assessing the risk of bias(Higgins et al.,2011, which covers: sequence generation, allocation concealment, blinding, incomplete outcome data (e.g. dropouts and withdrawals) and selective outcome reporting. For each domain in the tool, we will describe the procedures undertaken for each study, including verbatim quotes. A judgment as to the possible risk of bias on each of the six domains will be made from the extracted information, rated as 'high risk' or 'low risk'.

\section{Data Extraction and Analysis:-}

All reviewers were extracted data independently from each eligible study. Data abstracted were including and all reported patient-important outcomes. Therefore, it was decided to tabulate the data where appropriate and report the findings in a description manner. The following information was required: demographic information (study ID, number of patients) methodology (immediate loading, conventional loading), intervention details, (type of implants, type of attachments, period of follow up,) and outcomes on patients' satisfaction, quality of life, survival rate and prosthetic maintenances. Reviewers were resolve disagreements by discussion.

Meta-analyses were performed from studies on survival rates (odds ratio with random effects model). The reviewers (MH, AA,) extracted relevant information from the selected articles and entered it into a Microsoft Excel worksheet independently from each other. Due to the heterogeneity of outcome variables, and reporting, no meta-analysis was performed. 


\section{Identification of Studies:-}

Searches of the databases resulted in 124articles (Fig. 1) of these, 75 articles were excluded, as it was clear from the title and abstract that they did not fulfill the selection criteria. For the remaining 49 articles, 6 articles were duplicated, the remaining 43 full articles were obtained and following analysis of these, five potentially relevant studies were identified. 38 publications were excluded for the following reasons: case reports, non RCT, retrospective, cohort, studies not comparing mini implant with conventional implant. Therefore, 5 studies were included in the present study (Table 1).

\section{Quality of the Included Studies:-}

The quality of randomized controlled studies had high risk of bias (Omran et al 2013 and Jawad et al 2017) in random sequence generation and allocation concealment, while studies had low risk of bias blinding of outcome assessment, incomplete outcome data, and selective reporting. Fig $2 \& 3$

\section{Study Characteristics and Patient Populations:-}

Five papers compared between mini implant and conventional implant regarding patients satisfaction(Aunmeungtong, Kumchai, Strietzel, Reichart, \& Khongkhunthian, 2016)(de Souza et al 2015), quality of life(de Souza et al., 2015)(Jawad, Barclay, Whittaker, Tickle, \& Walsh, 2017), fracture incidence (Aunmeungtong et al 2016)(de Souza et al 2015), implant loss(Aunmeungtong et al., 2016)(de Souza et al 2015)(Jawad et al 2017)(Ribeiro et al 2015)( Omran et al 2013) and marginal bone loss(Aunmeungtong et al 2016)( Omran et al 2013).Table (1)

\section{Implant survival rate:-}

In total, 360 patients were included, 229 patients received 664 mini implants and 131 patients received 262 conventional implants. Follow-up periods up to one year reveal that for the mini implant groups 32 implants lost while in the conventional implant groups 1 implant lost. Mean implant survival rates to 1 year were $95.2 \%$ in the mini implants groups and $99.2 \%$ in the conventional implants groups. Table (2), Fig (4\&5)

\section{Patient satisfaction:-}

From the five eligible studies only two studies (Aunmeungtong et al 2016)(de Souza et al 2015) evaluated the patient satisfaction. They revealed that the patients was not statistical significant between the two treatments modalities. Fig.(6\&7)

\section{Marginal bone loss:-}

Only two articles(Aunmeungtong et al 2016)( Omran et al 2013) evaluated marginal bone loss and showed that no statistical significant difference between the treatment modalities however marginal bone loss was slightly higher in conventional group than mini implant group. Fig.(8)

\section{Fracture incidence:-}

From all studies only two(Aunmeungtong et al 2016)(de Souza et al 2015) evaluated fracture incidence and revealed that the fracture incidence is not statistically significant although it take place more in conventional group. Fig.(9\&10)

\section{Discussion:-}

This systematic review was done to decide if there is an actual variance between mini dental implant and conventional dental implant over-dentures in the tem of patient satisfaction and implant loss in addition to the peri implantitis complication that expressed as marginal bone loss. Patient's satisfaction is considered the most important patient related outcomes in the evidence based dentistry however there is no standard format to evaluate this outcomes. Visual analogue scale (VAS) is considered the most reliable scale to assess the patient satisfaction. Implant loss was reported by the number of implant lost during the follow up period. Peri-implantitis is an advanced damage of peri-implant tissue and can be assessed by gingival index, plaque index, pocket depth in addition to clinical attachment loss and marginal bone loss (MBL). But, in this review we choice the marginal bone loss as a parameter for peri-implantitis since it is the most essential indicator and most of trial basically evaluate periimplantitis via MBL measurement.

Comparing earlier systematic reviews in the similar subject which contain RCTs, prospective and retrospective studies, we attempt in this systematic review to focus on the mandibular implant retained over-denture to reach 
strong evidence by including only a randomized clinical trials because this type of studies is considered as a high quality studies in evidence based dentistry. Moreover, the preceding systematic reviews didn't include RCT comparing frankly both treatment modalities but instead they collected studies of mini dental implant, conventional dental implant separately and thereafter compared between them indirectly(Aparecido et al 2016).

Patient satisfaction with the overdenture studied by authenticated questionnaires established on a visual analogue scale (VAS)("Naert et al 2004) which considered the most important and most reliable scale.

One of the most reliable criteria to assess the success of the implant is loss of the osseointegration around the implant which lead to total loss of implant and consequently failure of prosthesis so implant loss was reported in this review by counting number of implant lost during the follow up period.

Regarding the assessment of peri implant condition which represented by the marginal bone loss, A minimum of 1year of follow- up was needed as major inclusion standard to diminish bias, according to the results reported by (Adell et al 1981)(Adell, Lekholm, Rockler, \& Brånemark, 1981) which reveal that the marginal bone loss around osseointegrated implants occurs mainly during the first year of function and tends to stabilize later (Ghelfan \& Chaushu, 2011).

Assessment of included studies for possible risk of bias was accomplished independently by the two reviewers (M.H and A.A) using Cochrane tool for risk of bias assessment which is considered as one of the most popular tools used by many researchers in the scientific field (Higgins \& Altman 2011).

The result of the meta-analysis revealed that mini dental implant resulted in more patient satisfaction compared with conventional dental implant but this difference was statistically insignificant, perhaps this result attained due to minimal surgical procedure and simple technique related to mini dental implant than conventional dental implant.

Regarding the implant loss the result of the meta-analysis revealed that the mini dental implant showed more implant loss when compared with conventional dental implant this difference was statistically significant.

Although the result of the meta-analysis revealed that mini dental implant resulted in less marginal bone loss when compared with conventional dental implant but this difference was statistically insignificant, perhaps this result attributed to the minimal surgical procedure and small diameter of the mini implant.

The limitations of this systematic review including; the total sample size of included studies was relatively small to reveal the actual influence of both treatment modalities and the include articles published only in English language could convey a source of bias.

Finally, analysis of this systematic review results must be accomplished with attentions as the included studies were very limited.

\section{Conclusion:-}

There is no strong evidence to reveal that mini implant could be used in the same degree as conventional dental implant however mini dental implant could be used as an alternative to conventional dental implant since it presents tolerable marginal bone loss, and enhancements in variables related to satisfaction of patients.

Conflict of interest: - There is no conflict of interest.

Funding: - Self-funding. 

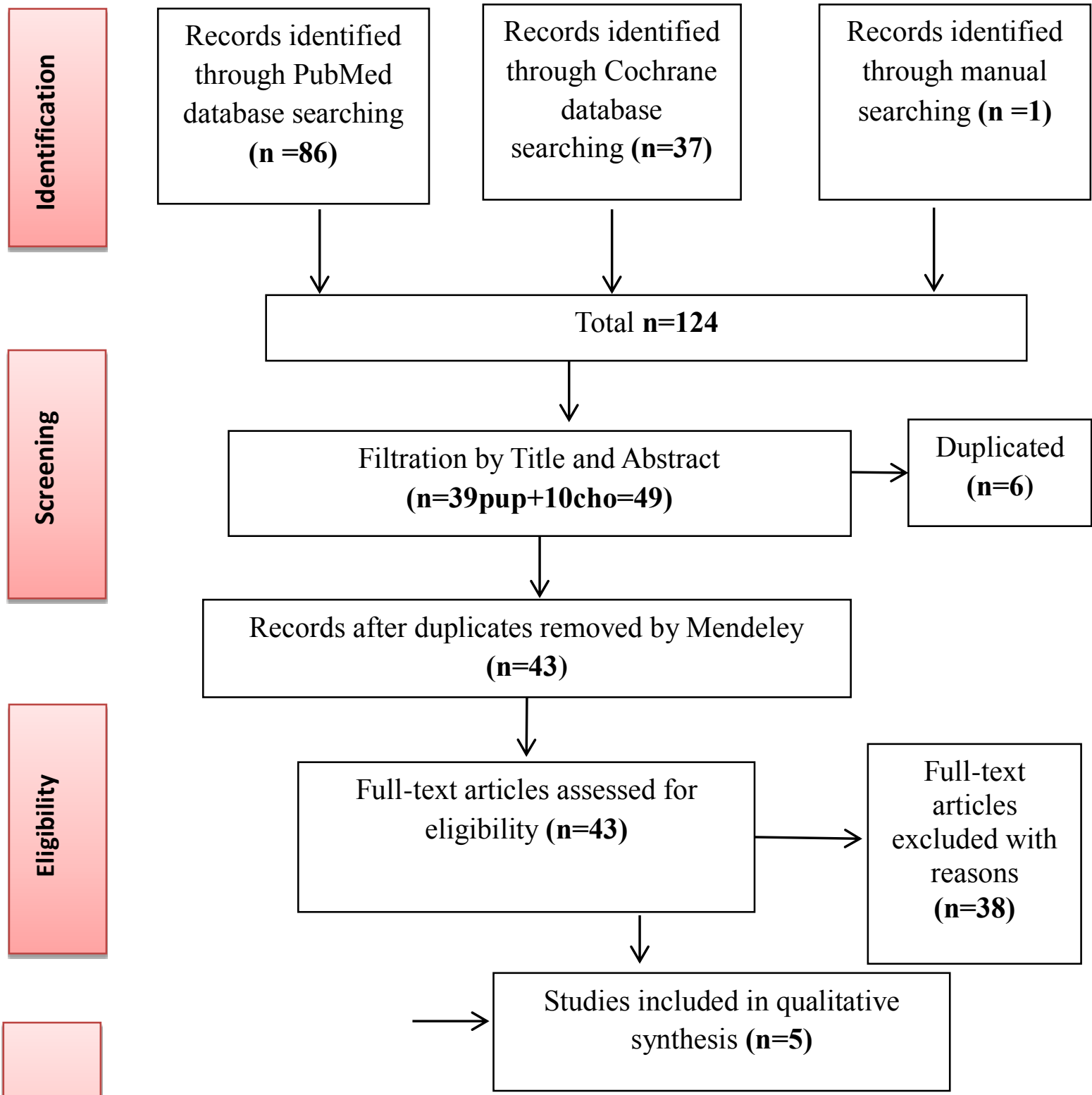

Figure 1:- prisma 2009 flow diagram: 


\begin{tabular}{|c|c|c|c|c|c|c|c|c|c|c|c|c|}
\hline Study ID & 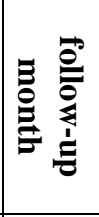 & 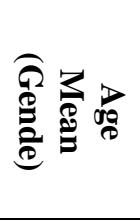 & 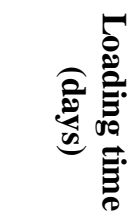 & 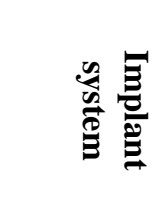 & 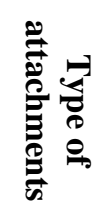 & 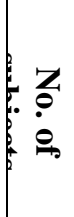 & 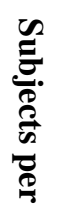 & 窇. & $\frac{E}{E}$ & 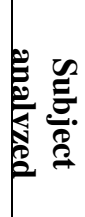 & 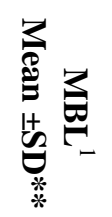 & 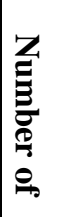 \\
\hline \multirow{3}{*}{$\begin{array}{l}\text { Aunmeungto } \\
\text { ng et } 2016\end{array}$} & \multirow{3}{*}{$\begin{array}{l}12 \\
\mathrm{~m}\end{array}$} & $\begin{array}{c}\mathrm{G} 1 \\
69.2 \\
\pm 11.2 \mathrm{y} \\
\end{array}$ & $\underset{\text { te }}{\text { immedia }}$ & \multirow{3}{*}{$\begin{array}{l}\text { (PW } \\
\text { plus) } \\
\text { Nakhon } \\
\text { Pathom, } \\
\text { Thailand) }\end{array}$} & $\begin{array}{c}\text { Equat } \\
\text { or }\end{array}$ & \multirow[t]{3}{*}{60} & 20 & $\stackrel{2}{2}$ & 40 & 20 & $\begin{array}{c}0.53 \pm \\
0.41\end{array}$ & \multirow[t]{2}{*}{0} \\
\hline & & $\begin{array}{c}\mathrm{G} 2 \\
66.65 \pm \\
6.28 \mathrm{y} \\
\end{array}$ & $\begin{array}{c}\text { immedia } \\
\text { te }\end{array}$ & & $\begin{array}{c}\text { Equat } \\
\text { or }\end{array}$ & & 20 & $\begin{array}{c}4 \\
\text { mini }\end{array}$ & 80 & 20 & $\begin{array}{c}0.60 \pm \\
0.45\end{array}$ & \\
\hline & & $\begin{array}{c}\mathrm{G} 3 \\
73.8 \pm 10 \\
.4 \mathrm{y}\end{array}$ & Delayed & & Ball & & 20 & $\begin{array}{c}2 \\
\text { stand }\end{array}$ & 40 & 20 & $\begin{array}{c}1.33 \pm \\
0.67\end{array}$ & 0 \\
\hline \multirow{3}{*}{$\begin{array}{l}\text { De Souza et } \\
\text { al } 2015\end{array}$} & \multirow{3}{*}{$12 \mathrm{~m}$} & \multirow{3}{*}{$\begin{array}{c}59.5 \pm \\
8.5 \mathrm{y}\end{array}$} & \multirow{3}{*}{ Delayed } & \multirow{3}{*}{$\begin{array}{c}\text { Boca } \\
\text { Raton, } \\
\text { FL, USA) }\end{array}$} & Ball & \multirow{3}{*}{$\begin{array}{c}12 \\
0\end{array}$} & 38 & $\begin{array}{c}4 \\
\text { mini }\end{array}$ & $\begin{array}{c}15 \\
2 \\
\end{array}$ & 35 & NR & $\begin{array}{c}? ? ? ? \\
?\end{array}$ \\
\hline & & & & & Ball & & 42 & $\begin{array}{c}2 \\
\text { mini }\end{array}$ & 84 & 36 & NR & 0 \\
\hline & & & & & Ball & & 40 & $\begin{array}{c}2 \\
\text { stand }\end{array}$ & 80 & 35 & NR & 0 \\
\hline \multirow{3}{*}{$\begin{array}{l}\text { RIBEIRO } \\
\text { et al } 2015\end{array}$} & \multirow{3}{*}{$7 d$} & \multirow{3}{*}{$\begin{array}{c}59.5 \pm \\
8.5 \mathrm{y}\end{array}$} & \multirow{3}{*}{ Delayed } & \multirow{3}{*}{$\begin{array}{c}\text {, } \\
\text { Morse- } \\
\text { Lock } \\
\text { Straight }\end{array}$} & Ball & \multirow{3}{*}{$\begin{array}{l}12 \\
0\end{array}$} & 38 & $\begin{array}{c}4 \\
\text { mini }\end{array}$ & $\begin{array}{c}15 \\
2\end{array}$ & 38 & NR & 0 \\
\hline & & & & & Ball & & 42 & $\begin{array}{c}2 \\
\text { mini }\end{array}$ & 84 & 42 & NR & \\
\hline & & & & & Ball & & 40 & 2 stand & 80 & 40 & NR & 0 \\
\hline \multirow{2}{*}{$\begin{array}{l}\text { jawad et al } \\
2017\end{array}$} & \multirow[t]{2}{*}{$6 \mathrm{~m}$} & \multirow[t]{2}{*}{ ???? } & \multirow[t]{2}{*}{ Early } & ASTRA & Ball & \multirow[b]{2}{*}{46} & 22 & 2 mini & 44 & 20 & NR & \\
\hline & & & & TECH® & Ball & & 24 & 2 stand & 48 & 22 & NR & 0 \\
\hline \multirow[t]{2}{*}{$\begin{array}{l}\text { Omran et al } \\
2013\end{array}$} & \multirow[t]{2}{*}{$12 \mathrm{~m}$} & \multirow[t]{2}{*}{$55 \mathrm{y}$} & $\begin{array}{c}\text { Mini } \\
\text { implant } \\
\text { immedia } \\
\text { te }\end{array}$ & $\begin{array}{c}\text { (Sendax } \\
\text { MDI } \\
\text { MAX; } \\
\text { IMTEC, } \\
\text { Corp., } \\
\text { Ardmore, } \\
\text { USA }\end{array}$ & Ball & \multirow[t]{2}{*}{14} & 7 & 4 mini & 28 & 28 & $\begin{array}{c}1.023 \\
\pm \\
0.122 \\
\mathrm{~mm}\end{array}$ & 0 \\
\hline & & & $\begin{array}{l}\text { Standard } \\
\text { Implant } \\
\text { Delayed }\end{array}$ & $\begin{array}{l}\text { Biohorizo } \\
\text { ns Co., } \\
\text { USA }\end{array}$ & Ball & & 7 & $\begin{array}{c}2 \\
\text { standa } \\
\text { rd }\end{array}$ & 14 & 14 & $\begin{array}{c}0.936 \\
\pm \\
0.099 \\
\mathrm{~mm}\end{array}$ & 0 \\
\hline
\end{tabular}

Table 1:- Characteristics of the included studies 


\section{Random sequence generation (selection bias)} Allocation concealment (selection bias)

Blinding of participants and personnel (performance bias)

Blinding of outcome assessment (detection bias)

Incomplete outcome data (attrition bias)

Selective reporting (reporting bias)

Other bias
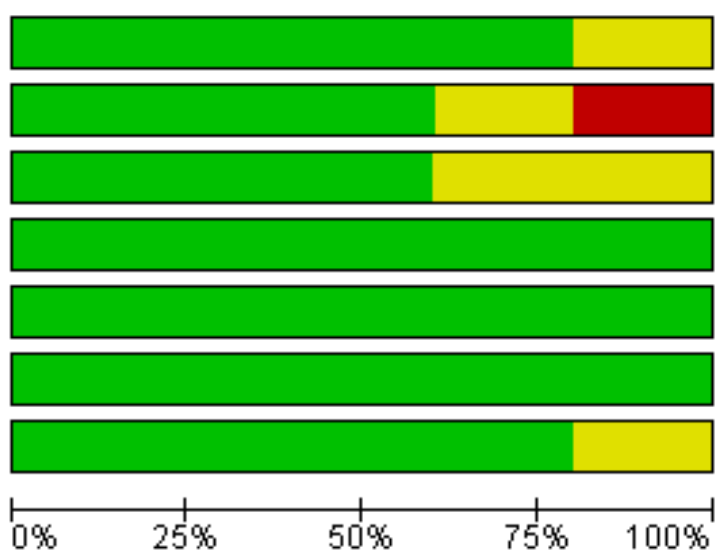

Fiwure (2):- Risk of bias graph:

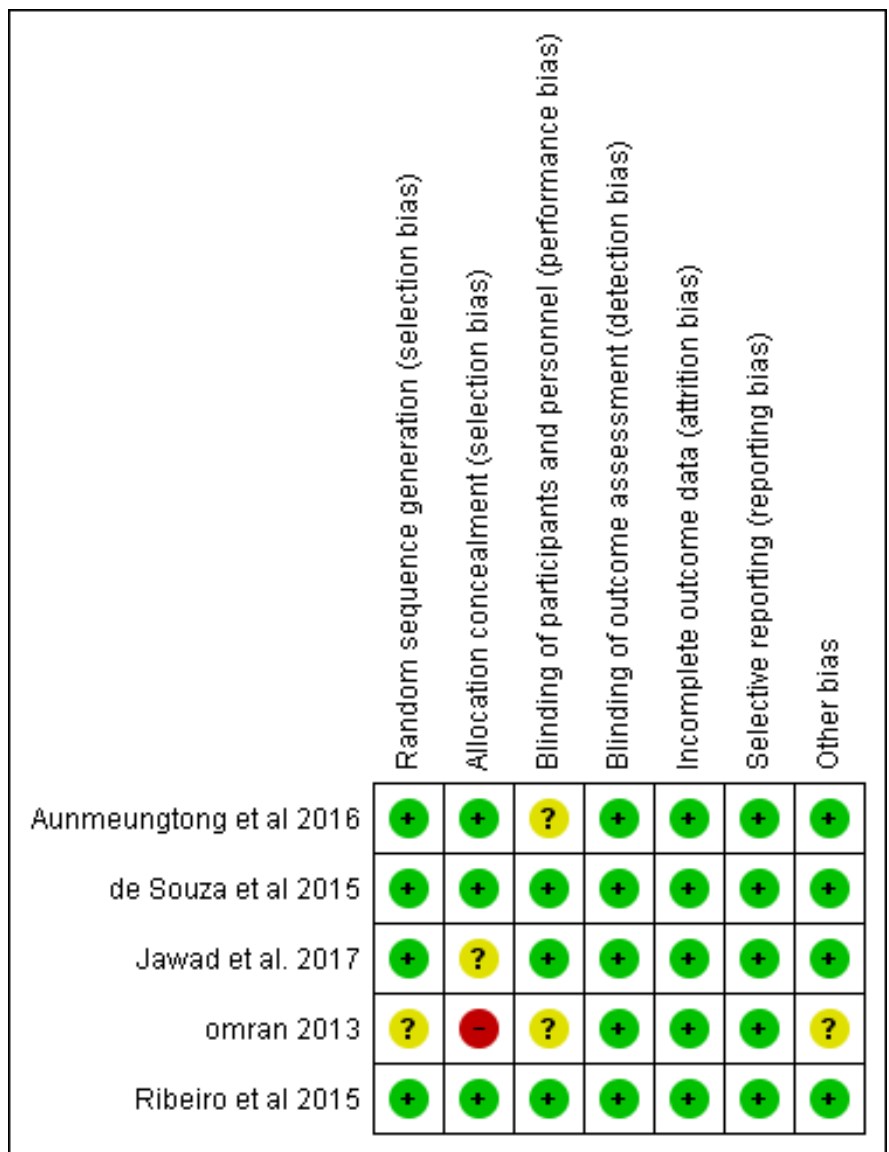

Figure 3:- Risk of bias summary 


\begin{tabular}{|l|c|c|}
\hline Study ID & $\begin{array}{c}\text { Implant survival rate } \\
\text { Mini implants }\end{array}$ & $\begin{array}{c}\text { Implant survival rate } \\
\text { Conventional implants }\end{array}$ \\
\hline Aunmeungtong et al 2016 & $100 \%$ & $100 \%$ \\
\hline de Souza et al 2015 & $86.8 \%$ & $100 \%$ \\
\hline omran 2013 & $100 \%$ & $100 \%$ \\
\hline Ribeiro et al 2015 & $100 \%$ & $100 \%$ \\
\hline Jawad et al. 2017 & $97.7 \%$ & \\
\hline
\end{tabular}

Table 2:- Implant survival rate

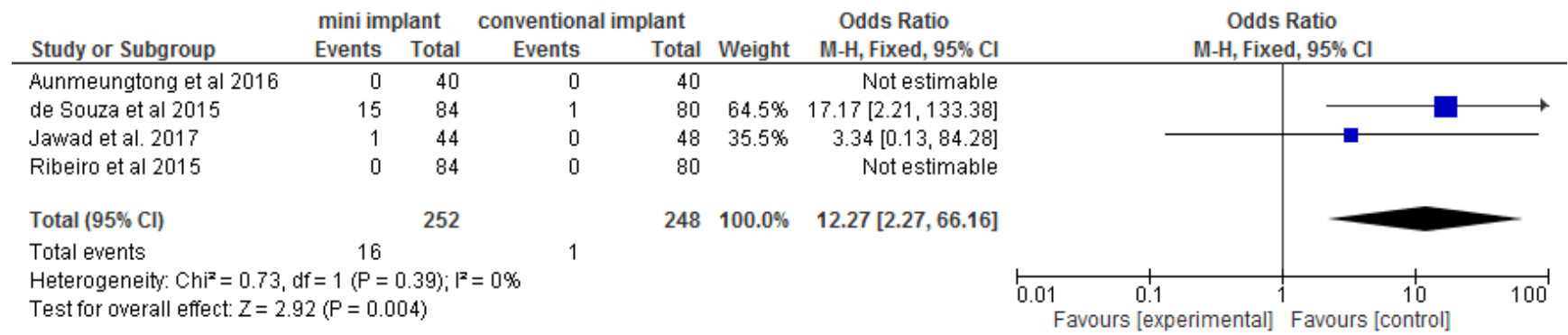

Figure 4:- Forest plot of Implant Survival two mini implants versus two conventional

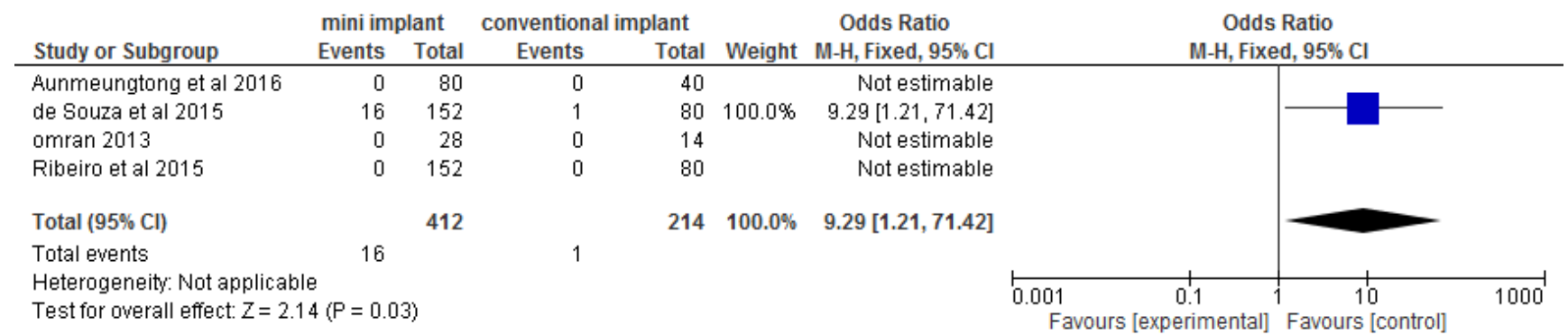

Figure 5:- Forest plot of Implant Survival four mini implants versus two conventional

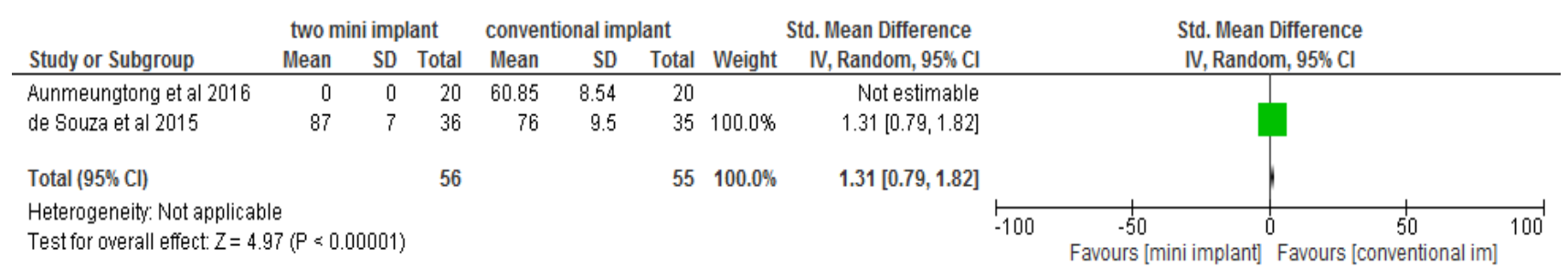

Figure 6:- Forest plot of Patient satisfaction two mini implants versus two conventional 


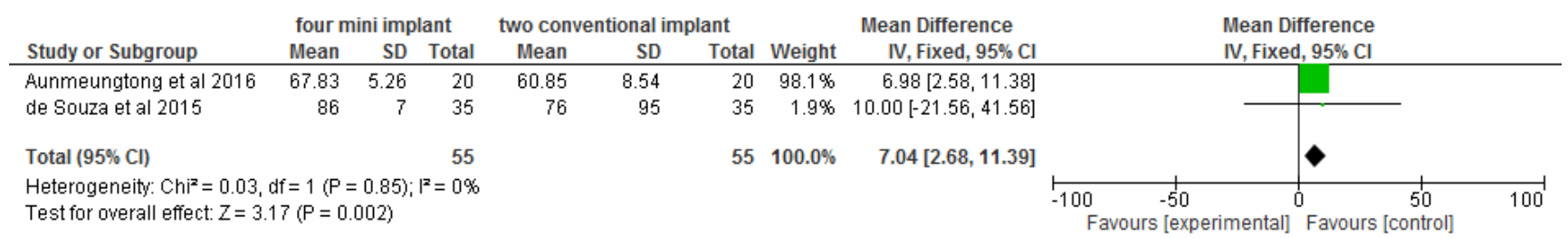

Figure 7:- Forest plot of Patient satisfaction four mini implants versus two conventional

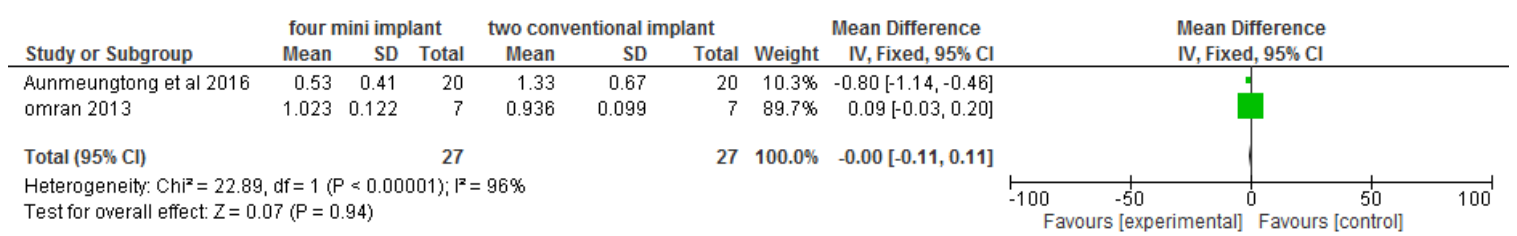

Figure 8:- Forest plot of Marginal bone loss four mini implants versus two conventional implant

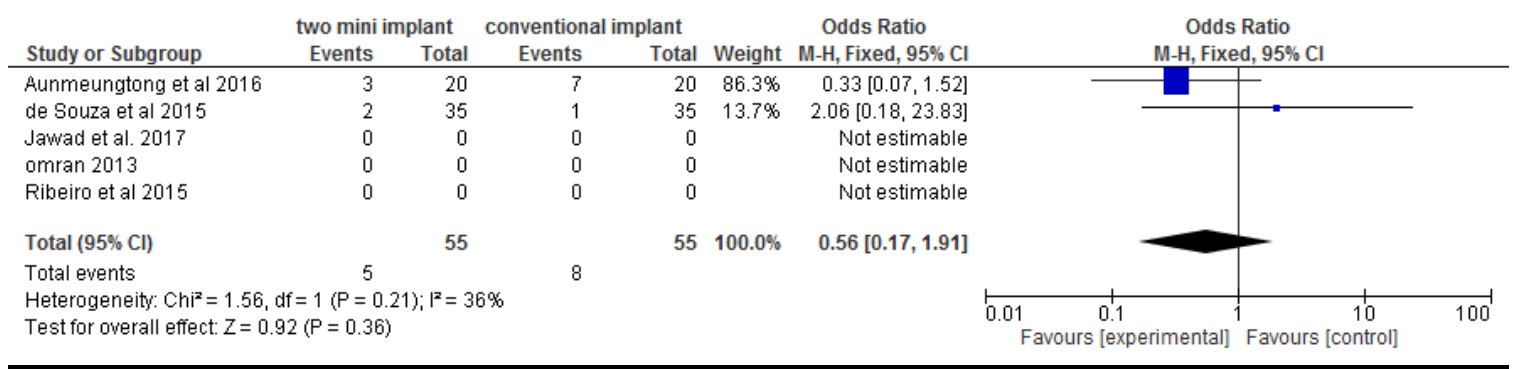

Figure 9:- Forest plot of Fracture incidence two mini implants versus two conventional

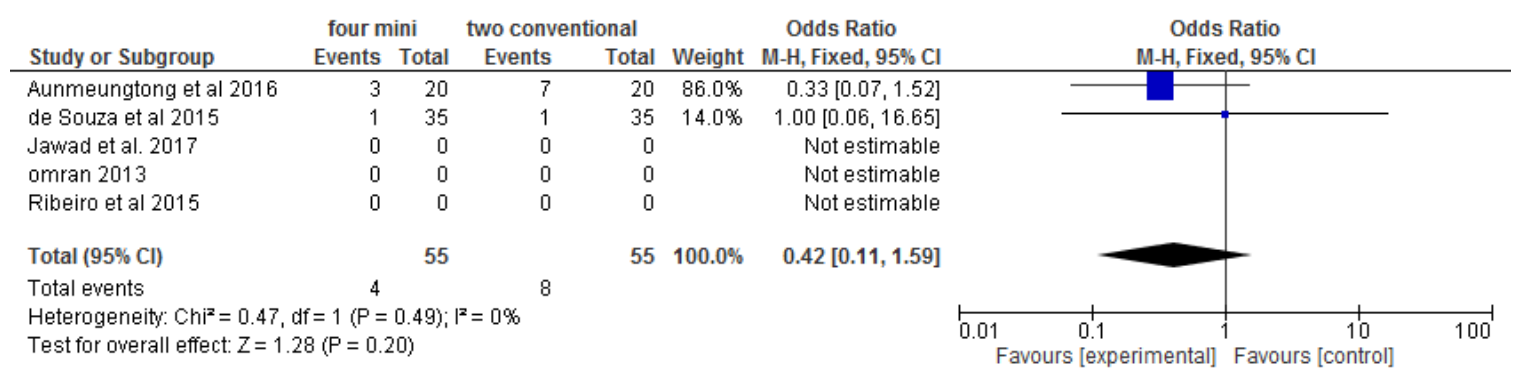

Figure 10:- Forest plot of Fracture incidence four mini implants versus two conventional

\section{References:-}

1. Adell, R., Lekholm, U., Rockler, B., \& Brånemark, P. I. (1981). A 15-year study of osseointegrated implants in the treatment of the edentulous jaw. International Journal of Oral Surgery, 10(6), 387-416.

2. Aparecido, C., Lemos, A., Verri, F. R., Eduardo, V., Batista, D. S., Ferreira, J., ... Pellizzer, E. P. (2016). Overdenture prosthesis retained by mini dental implants: A systematic review. Journal of Dentistry.

3. Aunmeungtong, W., Kumchai, T., Strietzel, F. P., Reichart, P. A., \& Khongkhunthian, P. (2016). Comparative Clinical Study of Conventional Dental Implants and Mini Dental Implants for Mandibular Overdentures: A Randomized Clinical Trial. Clinical Implant Dentistry and Related Research, 1-13.

4. Bidra, A. S., \& Almas, K. (2013). Mini implants for definitive prosthodontic treatment: A systematic review. The Journal of Prosthetic Dentistry, 109(3), 156-164.

5. Burns, D. R. (2000). Mandibular implant overdenture treatment: consensus and controversy. Journal of Prosthodontics : Official Journal of the American College of Prosthodontists, 9(1), 37-46.

6. de Souza, R. F., Ribeiro, A. B., Della Vecchia, M. P., Costa, L., Cunha, T. R., Reis, A. C., \& Albuquerque, R. F. (2015). Mini vs. Standard Implants for Mandibular Overdentures: A Randomized Trial. Journal of Dental Research, 94(10), 1376-84.

7. Doundoulakis, J. H., Eckert, S. E., Lindquist, C. C., \& Jeffcoat, M. K. (2003). The implant-supported overdenture as an alternative to the complete mandibular denture. Journal of the American Dental Association 
(1939), 134(11), 1455-8.

8. Feine JS, Carlsson GE, Awad MA, Chehade A, Duncan WJ, G. S. et al. (2002). . The McGill consensus statement on overdentures. Mandibular two-implant-overdentures as first choice standard of care for edentulous patients. Montreal, Quebec. Int J Oral Maxillofac Implants, 17:601-2.

9. Fitzpatrick BT. (2006). Standard of care for the edentulous mandible: a systematic review. The Journal of Prosthetic Dentistry, (95:71-8).

10. Ghelfan, O., \& Chaushu, D. M. D. G. (2011). Implant-Supported Partial Restorations, 26(5).

11. Higgins, J. P. T., \& Altman, D. G. (2011). Higgins 2011 Higgins JPT, Green S (editors). Cochrane Handbook for Systematic Reviews of Interventions. Version 5.1.0 [updated March 2011]. The Cochrane Collaboration, 2011. Cochrane Handbook for Systematic Reviews of Interventions.

12. Higgins JPT, Altman DG, Sterne JAC. Assessing risk of bias in included studies. In: Higgins JPT, Green S (eds). Cochrane Handbook for Sytematic Reviews of Interventions. Version 5.1.0. The Cochrane Collaboration, 2011. [Updated March 2011]. www.cochrane-h. (n.d.).

13. Jawad, S., Barclay, C., Whittaker, W., Tickle, M., \& Walsh, T. (2017). A pilot randomised controlled trial evaluating mini and conventional implant retained dentures on the function and quality of life of patients with an edentulous mandible. BMC Oral Health, 17(1), 53.

14. Moher, D., Liberati, A., Tetzlaff, J., Altman, D. G., \& Grp, P. (2009). Preferred Reporting Items for Systematic Reviews and Meta-Analyses: The PRISMA Statement (Reprinted from Annals of Internal Medicine). Physical Therapy, 89(9), 873-880.

15. Mostafa Omran 1, Alaa Abdelhamid 2, Amr Elkarargy 2, M. S. 3. (2013). Mini-Implant Overdenture Versus Conventional Implant Overdenture (A Radiographic and Clinical Assessments) Mostafa, 9(9), 89-97.

16. Naert I, Gizani S, Vuylsteke M, van Steenberghe D. A 5- year prospective randomized clinical trial on the influence of splinted and unsplinted oral implants retaining a man- dibular overdenture: prosthetic aspects and patient satis- faction. J Oral Rehabi. (n.d.).

17. Preoteasa, E., Imre, M., \& Preoteasa, C. T. (2014). A 3-year follow-up study of overdentures retained by minidental implants. The International Journal of Oral \& Maxillofacial Implants, 29(5), 1170-6.

18. Preoteasa, E., Meleşcanu-Imre, M., Preoteasa, C. T., Marin, M., \& Lerner, H. (2010). Aspects of oral morphology as decision factors in mini-implant supported overdenture. Romanian Journal of Morphology and Embryology = Revue Roumaine de Morphologie et Embryologie, 51(2), 309-14.

19. Ribeiro, A. B., Della Vecchia, M. P., Cunha, T. R., Sorgini, D. B., dos Reis, A. C., Muglia, V. A., ... de Souza, R. F. (2015). Short-term post-operative pain and discomfort following insertion of mini-implants for retaining mandibular overdentures: A randomized controlled trial. Journal of Oral Rehabilitation, 42(8), 605-614. 